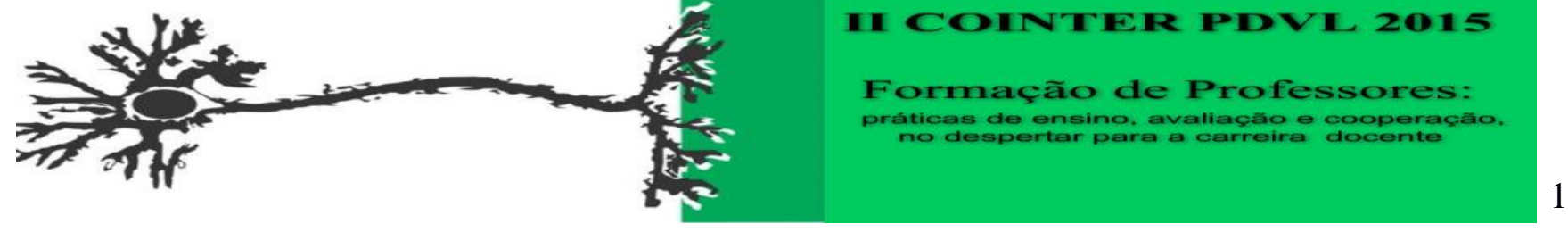

\title{
UMA AULA DE QUÍMICA SEGUINDO A TEORIA DOS MODELOS E O CICLO DA EXPERIÊNCIA KELLYANA
}

\author{
Apresentação: Comunicação Oral \\ Maria Tatiana da Silva Santos ${ }^{1}$; Cíntia de Abreu Arruda ${ }^{2}$; Ayrton Matheus da Silva Nascimento ${ }^{3}$ \\ Kilma da Silva Lima Viana ${ }^{4}$
}

\section{Resumo}

O presente trabalho foi realizado no Colégio Nacional de La Plata na Argentina, tendo como sujeitos estudantes de uma turma do penúltimo ano do ensino secundário, ou seja, segundo ano do ensino médio no Brasil. Teve como objetivo realizar uma aula na qual as ideias prévias/modelos que os alunos traziam em relação ao conteúdo que iríamos abordar, foram foco para a construção do conhecimento. Para isso utilizamos como base metodológica o ciclo da experiência Kellyana (CEK) o qual é fundamentado na Teoria dos Construtos Pessoais de George Kelly (1963). Com os resultados obtidos, pudemos observar que os estudantes aprimoraram suas hipóteses iniciais acerca do conteúdo que foi abordado no CEK e sedimentaram seus conhecimentos.

Palavras-Chave: Modelos; Ciclo da Experiência Kellyana; Ensino de Química;

\section{Introdução}

O processo de ensino-aprendizagem da Química é fundamental para promover a compreensão do que ocorre no nosso cotidiano, pois, é através desse processo que podemos entender as transformações que ocorrem no mundo e intervir nelas. A Química representa uma parte relevante em todas as ciências naturais, básicas e aplicadas, e de acordo com Cardoso e Colinvaux (2000), o estudo dessa ciência deve-se principalmente ao fato de possibilitar ao homem o desenvolvimento de uma visão crítica do mundo que o cerca, podendo analisar, compreender e utilizar este conhecimento no cotidiano, tendo condições de perceber e interferir em situações que contribuem para a deterioração de sua qualidade de vida.

Porém, nem sempre é fácil fazer com que o aluno entenda a importância de estudar essa ciência, e esse fato está relacionado, muitas vezes, às práticas tradicionais de ensino presentes nas

\footnotetext{
${ }^{1}$ Licenciatura em Química, IFPE - Campus Vitória de Santo Antão, mariatatiana015@hotmail.com

${ }^{2}$ Licenciatura em Química, IFPE - Campus Vitória de Santo Antão, cintiaarruda@outlook.com

${ }^{3}$ Licenciatura em Química, IFPE - Campus Vitória de Santo Antão, ayrthon.matheus@gmail.com

${ }^{4}$ Doutora em Ensino das Ciências (Física e Química), IFPE, kilma.viana@vitoria.ifpe.edu.br
} 
salas de aula, em que o professor limita a transmissão do conhecimento ao quadro, piloto e livro didático, e não relaciona os assuntos estudados com o dia-a-dia do estudante.

Nesse contexto, Pontes et al (2008), enfatiza que muitos estudantes demonstram dificuldades no aprendizado de química e, na maioria das vezes, não conseguem perceber o significado ou a importância do que estudam. Os conteúdos são trabalhados de forma descontextualizada, tornando-se distantes da realidade e difíceis de compreender, não despertando o interesse e a motivação dos alunos. Por isso, é importante que o professor busque inovar suas práticas, mostrando aos alunos a aplicabilidade dos assuntos, contribuindo assim para uma aprendizagem mais significativa.

Além da metodologia utilizada pelos professores, a avaliação é uma das formas que também desestimula muito os alunos para estudar, porque muitas vezes não alcançam uma boa nota nos exames, isso faz com que os mesmos não gostem da disciplina, porém, o problema não está no aluno e sim na forma como o conhecimento é transmitido e avaliado.

Como aborda Neira (2005), habitualmente, quando se fala em avaliação, são considerados, de forma prioritária ou mesmo exclusiva, os resultados obtidos pelos alunos. Concebendo a avaliação como algo que ocorre no fim de um ciclo didático. Porém, a avaliação deve ser contínua durante o curso.

Dessa forma, o ensino de Química deve ser conduzido antes de tudo, levando em consideração os conhecimentos prévios dos estudantes, é nesse sentido que entra a importância da avaliação diagnóstica, onde o professor conhece os modelos mentais dos alunos em relação a determinado conteúdo e assim pode ter uma direção de onde partir com o assunto a ser abordado.

Segundo Bunge (1976) “um modelo é uma construção imaginária de um (uns) objeto(s) ou processo(s) que substitui a um aspecto da realidade a fim de poder efetuar um estudo teórico por meio das leis e teorias usuais." (BUNGE 1976 apud GALAGOVSKY, GIACOMO, CASTELO, 2009).

Em relação ao ponto de vista da TCP (Teoria dos Construtos Pessoais), se aproxima da teoria dos modelos, pois considera o ser humano de forma semelhante a um cientista, onde desenvolve sistemas antecipatórios para lidar com os eventos que encontra durante sua vida.

Diante disso, o objetivo do presente trabalho foi realizar uma aula na qual as ideias prévias/modelos que os alunos traziam em relação ao conteúdo que iríamos abordar, foram foco para a construção do conhecimento.

\section{Fundamentação Teórica}


Do ponto de vista da TCP (Teoria dos Construtos Pessoais), de forma semelhante a um cientista, o ser humano desenvolve sistemas antecipatórios para lidar com os eventos que encontra durante sua vida. Quando esses sistemas não conseguem prever alguns eventos, eles podem ser reformulados, de acordo com as decisões tomadas por cada indivíduo. Dessa forma, o ser humano é visto através da metáfora do homem-cientista (KELLY, 1963).

A teoria dos modelos semelhante a TCP, considera que as hipóteses de partida identificam a teoria, e delas se deduzem as chamadas "consequências observacionais", enunciados singulares cujo teste empírico permite a constatação da teoria (cfr. Klimovsky, 1994, Cap. 10).

A partir das indagações, tanto da teoria dos modelos como da teoria dos Construtos Pessoais, todos os seres humanos possuem um modelo ou chamado pela TCP uma construção individual sobre um determinado assunto ou objeto, mesmo que nem sempre esteja concordando com o verdadeiro significado real que a teoria científica propõe.

Segundo Lombardi (2000), falar de modelos em ciências fáticas, pretendemos descrever os modelos fáticos, ou seja, um sistema abstrato que resulta de um processo de modelização, para assim alcançar o sistema real, cujas regularidades a teoria fática pretende descrever.

A validade de um modelo no campo das ciências fáticas deve se dar pela verificabilidade confronto com os fatos. A verificação não converte o modelo em 'verdadeiro', ou 'falso'. Os modelos não são nem verdadeiros nem falsos, são apenas mais ou menos adequados para certos usos. O valor e a significância de um modelo não são dados por algo intrínseco: dependerá do campo no qual vai ser aplicado, isto é, não será verdadeiro nem falso, mas sim útil ou inútil. (MARTINS, 2014).

Não existe "o" modelo do sistema real, se não uma multiplicidade de modelos segundo os fatores considerados relevantes, a eventual postulação de identidades ideais e de estruturas, etc. Por tanto, dado um certo sistema real não é possível considerar um dos seus modelos como melhor que outro em um sentido absoluto, se não só em relação aos objetivos específicos da particular investigação que se leva a cabo (LOMBARDI, 2000).

O mesmo ocorre com a TCP, cada pessoa constrói seus conceitos desenvolvendo sistemas de construções pessoais, que podem ser apenas parcialmente compartilhados. Em geral, a pessoa procura melhorar sua construção aumentando seu Repertório de construtos e/ou alterando-os para aperfeiçoar ou ajustar, ou ainda modificando a maneira como esses construtos estão estruturados (LIMA, 2008).

Assim, segundo a TCP, todas as interpretações humanas sobre o universo estão sujeitas à revisão ou substituição. Sempre existem construções alternativas. Esse posicionamento filosófico foi denominado “Alternativismo Construtivo" (LIMA, 2008). 
A importância de tais abordagens está em contextualizar conceitos científicos no marco histórico de sua formulação, assim como da necessidade de complementar o ensino de conteúdos com uma reflexão epistemológica acerca da própria atividade científica. Levando em consideração os conhecimentos prévios dos alunos, relacionando teoria e realidade, para assim ter significado a aprendizagem dos alunos. Diante disso, a prática docente deve reforçar a capacidade crítica do educando, sua curiosidade e sua insubmissão (FREIRE, 1996).

\section{Metodologia}

A pesquisa foi de natureza qualitativa, realizada no Colégio Nacional de La Plata na Argentina, tendo como sujeitos uma turma de estudantes do penúltimo ano do ensino secundário, ou seja, segundo ano do ensino médio no Brasil. Teve como objetivo realizar uma aula na qual as ideias prévias/modelos que os alunos traziam em relação ao conteúdo que iríamos abordar, foram foco para a construção do conhecimento, para isso utilizamos como base metodológica o ciclo da experiência Kellyana (CEK) o qual é fundamentado na Teoria dos Construtos Pessoais de George Kelly (1963).

Essa teoria é composta por 11 corolários, sendo um deles o Corolário da Experiência o qual afirma que o sistema de construção de uma pessoa muda à medida que ela constrói réplicas de eventos anteriores e as confronta com os eventos do presente. Nesse caso, quando a realidade não está de acordo com a réplica, a pessoa modifica seu sistema de construção. Esse processo de reconstrução está relacionado à ideia de Kelly sobre aprendizagem. Pois, para Kelly (1963), a aprendizagem não é algo especial que acontece apenas nas escolas, ou em algumas ocasiões, mas um processo diretamente ligado à vivência de uma experiência (LIMA, 2008).

Kelly define experiência como um ciclo composto por cinco etapas: Antecipação, Investimento, Encontro, Confirmação ou Desconfirmação e Revisão Construtiva.

O Ciclo da experiência Kellyana (CEK) começa na etapa da Antecipação, que é a etapa em que a pessoa usa os construtos que possui no seu sistema de construção e tenta antecipar um evento que está prestes a acontecer. Logo após a pessoa é engajada na etapa do Investimento, quando ela se prepara para se encontrar com o evento, momento esse de melhorar a construção da réplica através da introdução de novos saberes, nesse momento a pessoa é preparada para a etapa do Encontro o qual é caracterizada pelo momento específico no qual vai se deparar com o evento que antecipou. Em seguida, a pessoa avalia suas teorias pessoais, nesse momento que é a Etapa da Confirmação ou Desconfirmação, ela confirma ou desconfirma suas hipóteses iniciais através da vivência no evento. Para finalizar o ciclo, a pessoa é levada a reconstruir seus construtos, momento esse chamado de Revisão Construtiva. 
A primeira etapa, a Antecipação: Nesse momento realizamos uma avaliação diagnóstica com os alunos. Nessa avaliação continha uma pergunta sobre o que os alunos entendiam por uma reação de oxirredução e também na avaliação diagnóstica, existia algumas imagens de reações que ocorrem no cotidiano, pedindo que o estudante relatasse o que poderia está ocorrendo nelas e o que elas tinham em comum.

A segunda etapa, o Investimento: Nesse momento foi realizado a explanação do conteúdo referente às reações de oxirredução por meio de exemplos, e de forma interativa fazendo questionamentos aos alunos e levando em consideração suas hipóteses iniciais. Através disso, os alunos foram convidados a aprofundarem seus conhecimentos sobre o assunto em questão.

A terceira etapa, o Encontro: Nesse momento, foi proposto aos alunos a realização de uma prática experimental e a discussão sobre as observações referentes à mesma.

A quarta etapa, Confirmação ou Desconfirmação: Nesse momento, o aluno é abordado novamente e é feita as seguintes perguntas: "o que você sabia em relação ao conteúdo de oxirredução?" "E o que você sabe agora?" Averiguando se após a vivencia do encontro suas hipóteses iniciais foram confirmadas ou desconfirmadas.

Quinta e última etapa, Revisão Construtiva: Nesse momento, os estudantes foram convidados a relatarem sobre os exemplos que estavam presentes na avaliação diagnóstica, e dessa forma entendermos se tinham alcançados uma aprendizagem significativa.

\section{Resultados e Discussão}

A partir da vivência do CEK foi possível realizar as presentes discussões:

\section{- PRIMEIRA ETAPA DO CICLO DA EXPERIÊNCIA (ANTECIPAÇÃO)}

Nesse momento foi iniciado o Ciclo, no qual primeiramente foi realizada uma avaliação diagnóstica com os estudantes acerca do conteúdo que posteriormente seria abordado. Dessa forma, buscamos entender quais eram as ideias prévias que os estudantes possuíam acerca do assunto para depois disso, trabalharmos o conteúdo.

A partir da avaliação diagnóstica, onde perguntamos o que os estudantes entendiam por uma reação de oxirredução e o que ocorria em algumas imagens de exemplos do cotidiano sobre o tema e o que as mesmas tinham em comum, pudemos identificar algumas das concepções e associações presentes no pensamento dos sujeitos.

Em relação ao que eles entendiam sobre uma reação de oxirredução, mais de $50 \%$ dos alunos relataram não ter alguma ideia do que seria. Dos demais, alguns relacionaram a algo que se oxidava, em quanto outros foram mais específicos, como as seguintes respostas: 
“É uma reação química que se produz quando algum objeto se decompõe ao entrar em contato com o $\mathrm{O}_{2}$."

“É a Redução do Oxigênio."

"São reações Químicas que envolvem oxigênio."

Diante das respostas atribuídas, identificamos que os estudantes relacionaram as reações de oxirredução diretamente com a presença do oxigênio, e esse fato podemos associar à nomenclatura na qual o termo "oxirredução" por ser assim escrito "prediz" isso.

As imagens presentes na avaliação diagnóstica referentes a algumas reações de oxirredução foram entendidas de diversas formas, no caso da ferrugem, muitos alunos expressaram que ocorria a oxidação do ferro ao entrar em contato com o oxigênio, com isso podemos perceber que já existia algum conhecimento sobre o assunto, e isso tem que ser levado em consideração ao iniciar um conteúdo, pois o professor nem sempre necessita iniciar do zero para que o estudante compreenda, mas sim saber o que o mesmo já traz de bagagem, para com isso poder orientar sua aula, sabendo de onde pode partir e quais conceitos precisam ser esclarecidos, reforçados ou reformulados.

Já nos outros exemplos, como o da maça, fotossíntese, pilhas e baterias, a maioria dos alunos sentiram mais dificuldades em descrever o que poderia está acontecendo e o que as imagens tinham em comum. Nenhum estudante de início foi capaz de responder que em todas estavam ocorrendo uma reação de oxirredução.

Conhecendo as concepções dos alunos e os modelos mentais acerca do conteúdo, seguimos para a etapa do investimento para então podermos fazer as devidas reflexões acerca do assunto e com isso, melhorar a construção da réplica a partir da introdução de novos elementos.

\section{- SEGUNDA ETAPA DO CICLO DA EXPERIÊNCIA (INVESTIMENTO)}

Nesse momento, o conteúdo foi explanado de forma interativa com o aluno, explicando, por exemplo, que antes o conceito de oxidação era associado ao ganho de oxigênio, mas que com um tempo esse conceito precisou ser ampliado, pois esse fenômeno nem sempre ocorre dessa forma, exemplificando, assim, o caso de grãos de zinco em ácido clorídrico, no qual ocorre a oxidação, porém sem ganho de oxigênio.

A partir disso, explicamos o que seria uma reação de oxirredução por meio de alguns exemplos do cotidiano, como na fotossíntese, pilhas e baterias, maça apodrecida, e a corrosão de alguns metais. Foi feita uma discussão acerca do que acontecia com os elementos, por exemplo, quem estava oxidando e quem estava reduzindo e o que isso representava, ou seja, se ocorria ganho ou perda de elétrons.

No decorrer da aula, foram feitos questionamentos, e, de acordo com as respostas que os alunos davam, observamos que os mesmos tinham aprimorados seus conhecimentos acerca dos 
conceitos e saberes sobre o respectivo assunto.

Após essa etapa de ressignificação de conceitos e saberes, seguimos para etapa do encontro em que os estudantes realizaram experimentos acerca do assunto.

\section{- TERCEIRA ETAPA DO CICLO DA EXPERIÊNCIA (ENCONTRO)}

Nesse momento do encontro, os alunos foram convidados a se dividirem em grupos para a realização de uma prática experimental. A sala foi dividida em quatro (4) grupos em que cada equipe ficou com um metal para reagir em ácido clorídrico, sendo metais de Zinco, Alumínio, Estanho e Magnésio.

Instruímos os alunos sobre como realizar a experimentação, e pedimos que os mesmos observassem o que acontecia. Logo após, pedimos que um representante ou mais de cada grupo, escrevesse a reação correspondente a seu experimento no quadro e explicasse a seus colegas a partir de seus conhecimentos o que ocorreu em tais reações.

Com essa prática experimental, foi possível identificar que os alunos ao montarem a reação no quadro, observaram que eram reações de oxirredução, pois eles notaram que havia um elemento que se oxidava enquanto outro reduzia, e com isso ficou claro o envolvimento e a motivação dos estudantes na construção do conhecimento.

\section{- QUARTA ETAPA DO CICLO DA EXPERIÊNCIA (CONFIRMAÇÃO OU} DESCONFIRMAÇÃO)

No decorrer dessa etapa, fizemos as seguintes perguntas aos alunos: "O que você sabia em relação ao conteúdo de oxirredução?" "E o que você sabe agora?" Através desses questionamentos percebemos que alguns estudantes aprimoraram o que sabiam, pois antes associavam a oxidação somente quando se havia ganho de oxigênio, e depois da explicação modificaram seus conceitos.

Destacamos aqui algumas respostas que afirmam isso:

“Entendo que uma reação de oxirredução ocorre quando há uma mudança no número de oxidação. Um elemento se oxida, perdendo elétrons e outro reduz, ganhando elétrons. ”

"É uma reação química quando a perda e ganho de elétrons."

"É quando um elemento se oxida e outro se reduz."

Nessa perspectiva, é evidente que houve confirmação ou desconfirmação das ideias prévias dos alunos.

\section{- QUINTA ETAPA DO CICLO DA EXPERIÊNCIA (REVISÃO CONSTRUTIVA)}

$\mathrm{Na}$ etapa final do CEK, retomamos as discussões dos exemplos presentes na avaliação diagnóstica realizando alguns questionamentos para compreender se os alunos 
tinham sedimentado seus conhecimentos, e com as respostas do tipo: "Os exemplos da maça apodrecida, a formação do ferrugem, a fotossíntese e as pilhas e baterias são exemplos de reações de oxirredução, pois em ambas ocorrem a perda e ganho de elétrons simultaneamente", identificamos que de fato houve uma aprendizagem significativa e que e a revisão construtiva para aquele momento foi promovida.

\section{Conclusões}

Após a vivência do Ciclo da Experiência Kellyana obeservamos o quanto os estudantes participaram e se engajaram na atividade, desde a primeira etapa quando solicitamos que respondessem a avaliação diagnóstica para conhecermos os conhecimentos prévios, assim como na etapa do investimento em que se envolveram no estudo acerca do conteúdo abordado, e também na etapa do encontro, onde os estudantes se motivaram a participar da prática experimental e demostraram interesse em aprender.

Observamos também que na quarta etapa, os alunos puderam rever suas hipóteses e modifica-las, havendo assim uma evolução do que pensavam antes em relação ao que pensavam depois, como nos exemplos do cotidiano em que ocorria a oxirredução, pois, antes eles não reconheciam esse fenômeno, porém depois de se engajar no ciclo foram capazes de reconhecer, podendo sedimentar seus conhecimentos na quinta etapa.

Com esse trabalho, identificamos o quanto foi relevante a realização do CEK, visto que o sujeito é engajado em momentos de ação e reflexão, e isso faz com que eles compreendam melhor os assuntos e reflitam sobre o que estão aprendendo, superando assim, aquela ideia de aula de Química, por exemplo em práticas experimentais em que são apenas demonstrativas. No entanto, a prática realizada no ciclo foi do tipo investigadora, de problematização, onde todos os estudantes foram envolvidos nesse processo.

Essa atividade também foi importante porque fez a relação entre a teoria dos modelos com a teoria de Kelly, onde a ênfase da teoria de Kelly foi na questão metodológica na realização do CEK enquanto que a dos modelos, serviu de base para a fundamentação teórica, e ambas as teorias serviram para reflexão e realização do presente trabalho.

\section{Referências}

AUSUBEL, D.P. The psychology of meaningful verbal learning. New York, Grune and Stratton, 1963.

CARDOSO, S. P.; COLINVAUX, D. Explorando a Motivação para Estudar Química. Revista: Química Nova, 2000. 
FREIRE, P. Pedagogia da autonomia: saberes necessários à prática educativa. São Paulo: Paz e Terra, 1996.

GAlAGOVSKY, L.; GIACOMO, M. A.; CASTELO, V. Modelos vs. dibujos: el caso de la enseñanza de las fuerzas intermoleculares. Revista Electrónica de Enseñanza de las Ciencias, Buenos Aires, Argentina, Vol.8, No 1, 2009.

KELLY, G. A. A theory of personality: the psychology of personal constructs. New York: W.W. Norton, 1963.

KLIMOVSKY, G. Las desventuras del conocimiento científico. Una introducción a la epistemologia. Buenos Aires, A-Z Editora, 1994.

LIMA, K. S. Compreendendo as concepções de avaliação de professores de física através da teoria dos construtos pessoais. Recife, 2008. 163 p. Dissertação (Ensino das Ciências). Departamento de Educação, Universidade Federal Rural de Pernambuco, Recife, 2008.

LOMBARDI, O. La Noción de Modelos en Ciencias. Educación en Ciencias Vol. II. N 4-5, 2000.

MARTINS, G. A. Teorias e Modelos nas Ciências Administrativas. VI SEMEAD. Disponível em:

$<$ https://www.google.com.ar/url? sa=t\&rct=j\&q=\&esrc=s\&source=web\&cd=1\&cad=rja\&uact=8\&v ed=0CBsQFjAAahUKEwjRvNL12obJAhWChpAKHe8RAqg\&url=http\%3A\%2F\%2Fwww.ead.fea .usp.br\%2FSemead\%2F6semead\%2FADM\%2520GERAL\%2F054Adm\%2520-

$\% 2520$ Teorias $\% 2520 \mathrm{e} \% 2520$ Modelos\%2520nas\%2520Ci\%25EAncias\%2520Adm.doc\&usg=AFQj CNHVURMh9ZVRZZu6GGGF4EYilcoSWg\&bvm=bv.106923889,d.Y2I> Acesso em: 28/10/2015.

NEIRA, Marcos Garcia. Repensando a prática pedagógica. São Paulo: Mackenzie, 2005. (Avaliação da Aprendizagem)

PONTES, A. N.; SERRÃO, C. R.; FREITAS, C. K. A.; SANTOS, D. C. P.; BATALHA, S. S, A. O Ensino de Química no Nível Médio: Um olhar a Respeito da Motivação. Anais do XIV Encontro Nacional de Ensino de Química (XIV ENEQ), Paraná, 2008. 